\title{
Choked Inguino-Scrotal Hernia and Fistulising in the Scrotum at the Hospital Sominé DOLO of Mopti: A Clinical Observation
}

\author{
Abdoulaye Kanté1,2*, Djibril Traoré1, Siaka Diallo ${ }^{3}$, Drissa Ouattara ${ }^{3}$, Bréhima Bengaly3, \\ Drissa Traoré ${ }^{3}$, Moustapha Issa Magané ${ }^{4}$, Mariam Daou ${ }^{5}$, Nouhoum Ongoïba ${ }^{3}$
}

${ }^{1}$ Service of General Surgery, Sominé Dolo of Mopti Hospital, Bamako, Mali

${ }^{2}$ Laboratory of Anatomy of the Faculty of Medicine and Odontostomatology, Bamako, Mali

${ }^{3}$ Service of Surgery B, CHU Point G, Bamako, Mali

${ }^{4}$ Service of Anesthesia and Resuscitation, CHU Gabriel Touré, Bamako, Mali

${ }^{5}$ Service of Neurology, CHU Gabriel Touré, Bamako, Mali

Email: ^kanteim@yahoo.fr

How to cite this paper: Kanté, A., Traoré, D., Diallo, S., Ouattara, D., Bengaly, B., Traoré, D., Magané, M.I., Daou, M. and Ongoïba, N. (2019) Choked Inguino-Scrotal Hernia and Fistulising in the Scrotum at the Hospital Sominé DOLO of Mopti: A Clinical Observation. Surgical Science, 10, 71-75. https://doi.org/10.4236/ss.2019.103009

Received: February 11, 2019

Accepted: March 12, 2019

Published: March 15, 2019

Copyright $\odot 2019$ by author(s) and Scientific Research Publishing Inc. This work is licensed under the Creative Commons Attribution International License (CC BY 4.0).

http://creativecommons.org/licenses/by/4.0/

\begin{abstract}
We report a case of grave and rare surgical complications nowadays, which calls out to us on the necessity of a bigger raising sensitization on the coverage of the constrictions hernial at the adult. It is about a case of right inguino-scrotal hernia choked secondarily complicated with a scrotal coecostomie at a 64-year-old man. The delay in the care was in touch with a traditional treatment but also in the poverty of the patient which was a needy the total care of which was assured by the social services department of the hospital. The perioperative exploration found a cecostomy the mucous membrane of which was inverted in the opening of the stoma, an ulceration of the peristomial scrotum with a normal macroscopic aspect of the testicle homolateral. The care was made at single time: parage and scrotal suture more resection segmental of the coecum followed by an anastomosis ileocolic terminoterminal and a cure of the hernia according to Shouldice. The operating suites were simple with ablation of the threads to operating J12 comment and the liberation of the patient the next day. The clinical evolution was satisfactory with a backward movement of 4 years.
\end{abstract}

\section{Keywords}

Choked, Grown-Up Hernia, Scrotal Coecostomie

\section{Introduction}

The hernia constriction is a surgical urgency. Its incidence is estimated between 
$4 \%$ and $18 \%$ for the inguinal hernias [1] [2]. The forecast depends on the extension of the coverage in surgical environment. This extension is often extended in developing countries for diverse reasons [1]. We report a case of inguino-scrotal hernia choked secondarily complicated with a scrotal cecostomy at a 64-year-old man. The objective of this work is to remind the gravity and the complexity of the coverage of the evolutionary complications of the inguino-scrotal hernias and to promote their treatment of surgical premature.

\section{Observation}

It is about a 64-year-old man, a shepherd, who was admitted in the regional hospital of Mopti for scrotal wound further to a right inguino-scrotal tumefaction. This scrotal wound appeared for one year was associated at the beginning with a painful right inguino-scrotal tumefaction associated with food vomiting then bilious, what motivated a consultation to a traditherapeute of closeness where a treatment with decoction and with powder would have been recommended to the patient. This has entrained a forgiveness of the pain with a scrotal followed ulceration a few days later by the external scrotal fistulisation and spontaneous preparation of a scrotal coecostomie fault which took out saddles and so condemning the anus or at least putting at rest the anus.

The interrogation of the patient found the existence of several previous consultations for painful right inguino-scrotal tumefaction handled to the same tradipractitioner successfully according to him by analgesic traditional ones and spontaneous reductions. In front of the absence of improvement of the scrotal wound and the impossibility to make the sexual act, the patient consulted in a health center which we then referred him. The clinical examination of the patient, in the external consultation, objectified: a good general state, an apyrexie, a right inguino-scrotal tumefaction with a scrotal coecostomie through which went out saddles, scrotal ulceration died stomial, a defenseless supple belly nor a spasm (Figure 1).

The diagnosis of choked right inguino-scrotal hernia complicated with a scrotal coecostomie was put. The balance sheet of operability was normal.

The coverage began with hospitalization of the patient with care of the stoma. The surgical operation realized under cold conditions under general anesthesia

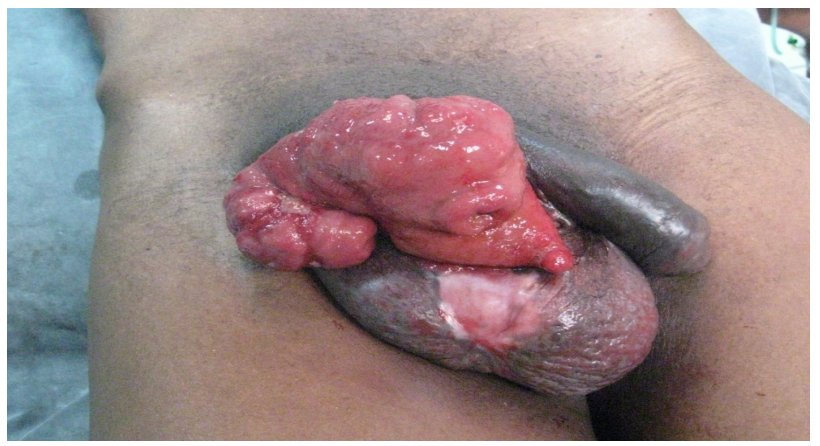

Figure 1. Right inguino-scrotal hernia complicated with a scrotal coecostomie. 
with orotracheal intubation, consisted of liberation of the scrotal stoma by scrotal section (Figure 2).

After liberation coeco-appendicular, it existed a perforing copeels wide $10 \mathrm{~cm}$ on 4 of the diameter serving as the stomial opening with evagination of the mucous membrane coeco-appendicular.

The peritoneal cavity was clean and there was a perforing of the segment herniated ileal inside the hernial sac.

A resection copeels taking the appendix, the ileocoecal opening and first $\mathrm{cm}$ of the ileum followed by an anastomosis ileocolic terminoterminal was realized. After reinstatement of the anastomosis a right inguinotomy was realized. The exploration of the inguino-scrotal region highlighted a normal macroscopic aspect of the testicle homolateral which motivated the realization of the cure of the hernia according to the technique of Shouldice and the scrotal parage with preservation of the testicle after implementation of two blades of drain in the scrotum (Figure 3).

A triple post-operative antibiotic treatment by parenteral way was established (ceftriaxone $1 \mathrm{~g}$ in IV/12H, gentamycin $160 \mathrm{mg}$ in IM/24H and metronidazole $500 \mathrm{mg} / 12 \mathrm{H})$.

The operating suites were simple with the ablation of two blades of drain to J3, the cutaneous sons to J12 and the exit of the sick person to J13 (Figure 4).

The patient was regularly followed with a backward movement of 4 years. The clinical evolution was favorable with a scar not retractile and normal resumption of the sexual activity.

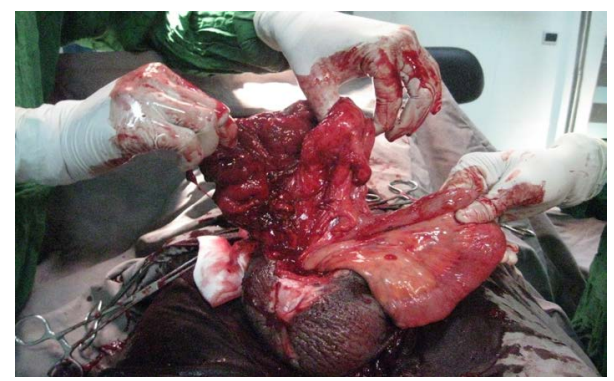

Figure 2. Liberation of the scrotal coecostomie.

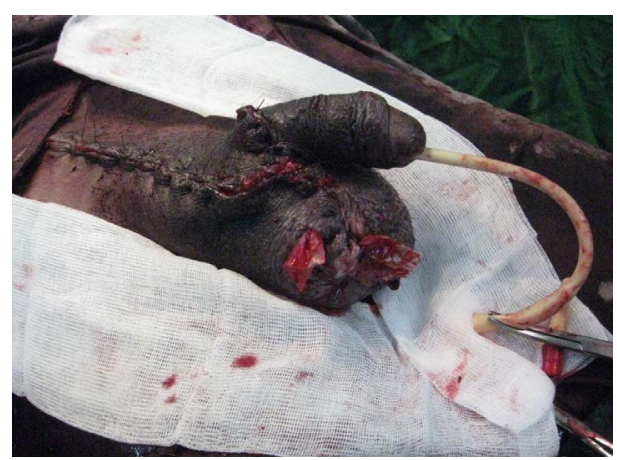

Figure 3. Cure of the hernia according to Shouldice and parage scrotal with implementation of two blades of drains in the scrotum. 


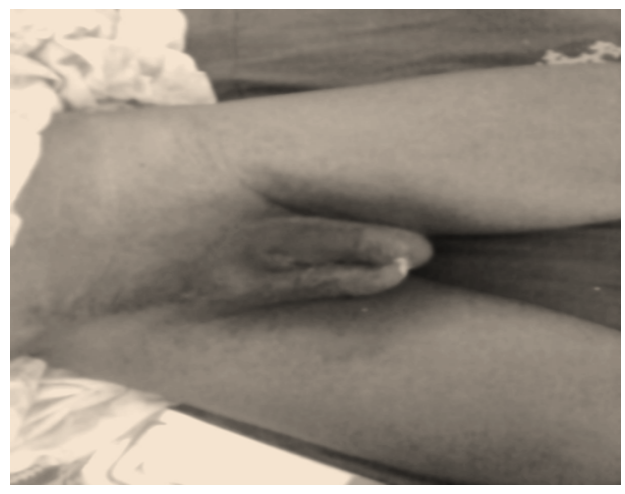

Figure 4. Healing completes to J12.

\section{Discussion}

The clinical case which we report concerns a 64-year-old male patient having trained a right inguino-scrotal hernia for 1 year. He consulted one year after the report of a coecostomie and an impossibility to realize the sexual act, for lack of traditional treatments and of financial means according to him, while Chirdan in Nigeria and Roshan in India [3] [4] considered that it is the ignorance of the evolutionary risks of the inguinal hernia which is at the base of the delay in the consultation. The male sex and the affection of the right-hand side at our patient are also brought back in the literature [1] [2].

In our observation the homolateral testicle had a normal macroscopic aspect and were just like preserved in the studies reported by Chirdan, Roshan, Sowande [3] [4] [5]. Harouna [6] reported a case of necrosed testicle which motivated an orchidectomie.

Contrary to Shahbaz [7] who found approximately $100 \mathrm{ml}$ of pus in the cavity abdominal, we found a peritoneal cavity clean and a coecum drilled in the hernial sac where from left the fistulisation.

A resection copeels taking the appendix, the ileocoecal opening and first $\mathrm{cm}$ of the ileum followed by an anastomosis ileocolic terminoterminal was realized. After reinstatement of the anastomosis by the right inguinotomie, the cure of the hernia according to the technique of Shouldice and the scrotal parage ended the intervention. The operating suites were simple for our patient as in the studies reported by Chirdan and Roshan [3] [4], while for the case reported by Tapsoba [8] a post-operative extension of the phlegmon motivated the resumption of the unbridling associated with a diversion of saddles by a colostomy. Sowande [5] reported a post-operative peritonitis by desertion of the anastomosis ileal.

\section{Conclusion}

Except an operating contraindication, any inguinal hernia must be operated before the arisen of the complications. The simplicity of the surgical coverage of the inguinal hernia as well as the good post-operative forecast, owing this clinical observation should question to the various factors involved in the accessibility of the care in urban zones Malian. 


\section{Acknowledgements}

1) Service social of the hospital Sominé Dolo for the total coverage of the patient.

2) All the authors for their contribution.

\section{Autoriastion of the Patient}

We undersigned, authors of this article, give evidence that the patient gave us the authorization for the publication of his images.

\section{Conflicts of Interest}

We, authors of this article declare that there is no conflict of interests.

\section{References}

[1] Anoukoum, T., Agoda-Koussema, L., Attipou, K. and Ayité, A. (2009) Choked Inguino-Scrotal Hernia and Fistulisée in the Scrotum: Coverage (Care) and Precautionary Measures about an Observation. African Journal of Digestive Surgery, 9 , 876-878.

[2] Rattan, K.N. and Garg, P. (1998) Neonatal Scrotal Faecal Fistula. Pediatric Surgery International, 13, 440-441. https://doi.org/10.1007/s003830050363

[3] Chirdan, L.B., Uba, A.F., Iya, D. and Dakum, N.K. (2004) Spontaneous Scrotal Faecal Fistula in a Neonate: Report of a Case. Nigerian Journal of Surgical, 6, 59-60.

[4] Roshan Khan, T., Maletha, M. and Tandon, R. (2009) Neonatal Incarcerated Inguinal Hernia with Spontaneous Scroto-Fecal Fistula. Paediatrics Journal of Surgery, 44, 1846-1847. https://doi.org/10.1016/j.jpedsurg.2009.04.020

[5] Sowande, O.A., Adejuyigbe, O., Ogundoyin, O.O., Uba, A.F. and Chinda, J.Y. (2006) Spontaneous Scrotal Faecal Fistula: A Rare Complication of Incarcerated Inguinal Hernia in Infancy. Journal of India Journal of Pediatric Surgery, 11, 244-245. https://doi.org/10.4103/0971-9261.29610

[6] Harouna, Y., Gamatie, Y. and Abarchi, H. (2001) The Inguinal Hernias of the Child: Review of the Literature. African Journal of Medicine, 5, 48.

[7] Shahbaz, H.F., Bushra, S., Mohd, A.K., Afzal, A. and Asmat, A.S. (2013) Supra Pubic Fecal Fistula Due to Richter Inguinal Hernia: A Case Report and Review of Literature. Iranian Journal of Medical Sciences, 38, 129-131.

[8] Tapsoba, W., Nandiolo-Anelone, K.R. and Baonkolé, S.R. (2012) Consequences Formidable of a Choked Inguinal Hernia Neglected in the CHU of Treichville, Ivory Coast. Journal of Surgery, 14, 110-113. 